\title{
Comunicação
}

[Communication]

\section{Inclusões intracitoplasmáticas hialinas na medular da adrenal de bovinos}

[Intracytoplasmic hyaline inclusions in adrenal medulla of bovine]

\author{
L.P. Mesquita, C.C. Abreu, F. Wouters, M.S. Varaschin, P.S. Bezerra Jr* \\ Departamento de Medicina Veterinária - UFLA \\ Caixa Postal 3037 \\ 37200-000 - Lavras, MG
}

A glândula adrenal é composta por duas regiões distintas: o córtex e a medular. Um dos componentes principais da região medular são as células cromafins, as quais são neurônios simpáticos modificados que sintetizam epinefrina e norepinefrina distintamente (Hullinger e Andrisani, 2006).

Inclusões intracitoplasmáticas hialinas em células cromafins, denominadas glóbulos hialinos ou corpúsculos da adrenal, têm sido descritas em várias espécies animais de laboratórios (McConnel e Talley, 1977) e humanos (Hart e Cyrus, 1968; Sugie et al., 2005). Acredita-se que estas inclusões se formem em decorrência de uma estimulação intensa da adrenal ocasionada por algumas doenças infecciosas, tóxicas e neurodegenerativas (Hart e Cyrus, 1968; McConnel e Talley, 1977). Um número desproporcionalmente alto dessas inclusões é relatado em doenças neurológicas de humanos (Hart e Cyrus, 1968), e na doença de Parkinson tem sido encontrado maior número dessas inclusões (Sugie et al., 2005). Corpúsculos semelhantes também foram descritos em casos de raiva em humanos (Almeida et al., 1986).

Dados sobre inclusões intracitoplasmáticas hialinas em células cromafins da adrenal de bovinos não têm sido relatados. O objetivo deste trabalho foi realizar um estudo retrospectivo dessas inclusões em bovinos.

Entre 1999 e 2009 foram necropsiados 367 bovinos dos quais 20 tiveram as adrenais coletadas. Nestes, o diagnóstico final foi obtido por meio de exames macro e microscópicos. Nos casos de raiva, amostras de encéfalo foram enviadas para a imunofluorescência direta no Instituto Mineiro de Agropecuária (IMA). As adrenais foram fixadas em formol a $10 \%$ tamponado, desidratadas em concentrações crescentes de álcool etílico, diafanizadas em xilol e incluídas em parafina. Cortes de $5 \mu \mathrm{m}$ foram corados pela hematoxilina e eosina e pelo ácido periódico de Schiff (PAS). Nos casos de raiva, cortes das adrenais foram submetidos a imunoistoquímica (IHQ) para pesquisa de antígenos virais nas inclusões conforme protocolo preestabelecido (Pedroso et al., 2008). Como controle positivo foi utilizado corte do sistema nervoso de bovino positivo para raiva na imunofluorescência direta e previamente testado na IHQ.

Das 20 adrenais coletadas, sete apresentaram inclusões em diferentes intensidades, sendo três casos de animais com raiva, dois com broncopneumonia supurativa crônica, um caso com peritonite supurativa crônica e um com mastite gangrenosa. Maior número de inclusões foi encontrado nos casos de raiva e em um de broncopneumonia supurativa crônica. Todos os três casos de raiva apresentavam inclusões frequentes.

Inclusões intracitoplasmáticas, eosinofílicas, arredondadas, únicas ou múltiplas, de tamanhos variados, fortemente coradas pelo PAS, foram observadas nas células cromafins da medular da adrenal. A morfologia das inclusões encontradas

Recebido em 23 de março de 2010

Aceito em10 de janeiro de 2011

* Autor para correspondência (corresponding author)

E-mail: bezerraj@dmv.ufla.br 
foi semelhante à descrita na literatura para outras espécies animais (McConnel e Talley, 1977) e para humanos (Hart e Cyrus, 1968; Sugie et al., 2005).

As inclusões em todos os casos estavam presentes nas camadas externa e interna da medular, embora fossem mais frequentes na primeira. Nesta camada, existem principalmente dois tipos histológicos de células: as colunares, relacionadas à síntese de epinefrina, e as epitelioides, relacionadas à produção de norepinefrina (Hullinger e Andrisani, 2006). McConnel e Talley (1977), por meio da microscopia eletrônica, detectaram inclusões nos dois tipos celulares. No entanto, Sugie et al. (2005) detectaram inclusões somente nas células que sintetizam norepinefrina, uma vez que essas células foram imunonegativas para feniletanolamina $\mathrm{N}$-metiltransferase, enzima que converte a norepinefrina em epinefrina. Nas adrenais do presente estudo, não foi possível observar diferenças na distribuição das inclusões entre os tipos celulares descritos.

Na medular da adrenal dos casos de raiva, foi observada inflamação não supurativa multifocal leve a moderada, como descrita em outras espécies (Almeida et al., 1986). Nestes casos, as inclusões mostraram-se negativas na imunoistoquímica, descartando a possibilidade de serem inclusões virais como sugerido em estudo prévio (Almeida et al., 1986). Alguns autores ressaltaram que as inclusões foram encontradas somente em adrenais que possuíam algum tipo de alteração como necrose ou hemorragia (McConnel e Talley, 1977). No presente estudo, verificou-se que havia corpúsculos em adrenais sem outras alterações histológicas, embora nos casos de raiva, onde os corpúsculos foram mais frequentes, as adrenais apresentassem inflamação concomitante.

A correlação entre determinadas enfermidades e o desenvolvimento de inclusões não é conhecida. Porém, tem sido sugerido que essas inclusões representam um estado degenerativo das células cromafins (McConnel e Talley, 1977; Sugie et al, 2005) o qual, ao menos em humanos, provavelmente ocorra também em adrenais normais, embora em pequena quantidade (Sugie et al., 2005). Na doença de Parkinson em humanos, também se associou a presença das inclusões à secreção prolongada de norepinefrina por estas células (Sugie et al., 2005). Os dados do presente trabalho demonstraram que, em bovinos, as inclusões intracitoplasmáticas hialinas na medular da adrenal podem ser encontradas em associação à raiva e a doenças bacterianas crônicas. Um estudo mais frequente das glândulas adrenais de bovinos é necessário para o melhor entendimento da patogênese dessas inclusões nesta espécie e a possíveis manifestações clínicas nos animais afetados.

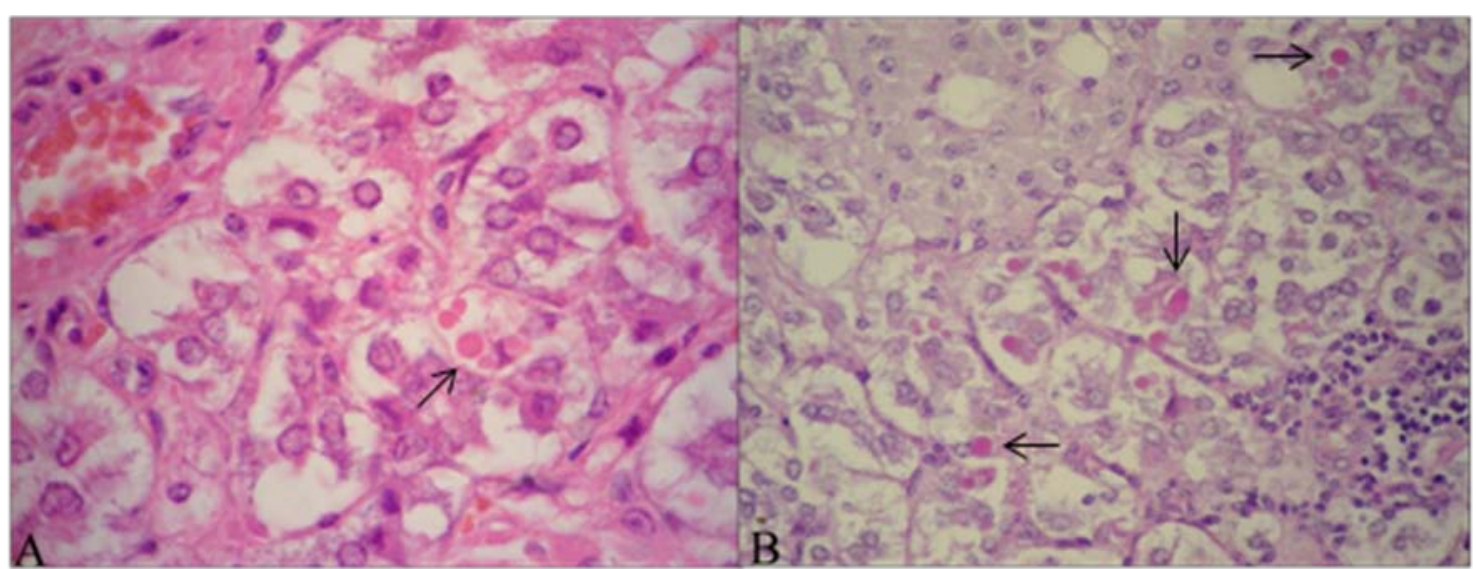

Figura 1. Bovino, medular da adrenal. A. Inclusões intracitoplasmáticas eosinofílicas arredondadas, múltiplas e de tamanhos variados em células cromafins (seta). HE, obj. 100. B. Inúmeras inclusões intracitoplasmáticas fortemente coradas pelo ácido periódico de Schiff em células cromafins (setas) de bovinos com raiva. Nota-se, também, infiltrado inflamatório linfocitário. PAS, obj. 40X.

Palavras-chave: bovino, adrenal, inclusão citoplasmática, glóbulos hialinos, raiva 


\begin{abstract}
Cytoplasmic inclusion bodies in adrenal medullary chromaffin cells have been described in various species including humans. These inclusions are believed to be related to certain infectious, toxic and neurodegenerative diseases. No reports concerning such adrenal inclusions have been described in bovines. Adrenal glands from twenty bovines were evaluated in a retrospective study. Seven of these exhibited inclusions - three cases of rabies, two cases of chronic suppurative bronchopneumonia, one case of chronic suppurative peritonitis, and one case of gangrenous mastitis. The inclusions were present in higher numbers especially in cases of rabies and also in one case of chronic suppurative bronchopneumonia. The inclusions were intracytoplasmic, eosinophilic, rounded, single or multiple, of various sizes, strongly stained by PAS and were present in higher numbers in the external layer of the adrenal medulla. The inclusions were negative when subjected to immunohistochemistry for detection of viral antigens in the cases of rabies. Although inclusion bodies were present in adrenal glands devoid of other histological alterations, they were more abundant in cases in which the adrenal gland had other alterations. The correlation between certain diseases and the development of inclusion bodies is not known, which highlights the importance of further studies on these inclusions in adrenal glands of bovines.
\end{abstract}

Keywords: cattle, adrenal, cytoplasmic inclusion, hyaline globules, rabies

\section{REFERÊNCIAS BIBLIOGRÁFICAS}

ALMEIDA, H.O.; TEIXEIRA, V.P.A.; OLIVEIRA, G.; BRANDÃO, M.C.; GOBBI, H. Medulite suprarrenálica em casos de raiva humana. Mem. Inst. Oswaldo Cruz, v.81, p.439442, 1986.

HART, M.N.; CYRUS, A. Hyaline globules of the adrenal medulla. Am. J. Clin., v.49, p.387391, 1968.

HULLINGER, R.L.; ANDRISANI, O.M. Endocrine system. In: EURELL, J.A.C.; FRAPPIER, B.L. Dellmann's textbook of veterinary histology. 6.ed. Oxford: Blackwell, 2006. p.311-316.
McCONNEL, E.E.; TALLEY, F.A. Intracitoplasmatic hyaline globules in the adrenal medulla of laboratory animals. Vet. Pathol., v.14, p.435-440, 1977.

PEDROSO, P.M.O.; PESCADOR, C.A.; BANDARRA, P.M. et al. Padronização da técnica de imuno-histoquímica para raiva em amostras de tecido do sistema nervoso central de bovinos fixadas em formol e emblocadas em parafina. Pesq. Vet. Bras., v.28, p.627-632, 2008.

SUGIE, M.; GOTO, J.; KAWAMURA, M. Increased norepinephrine-associated adrenomedullary inclusions in Parkinson's disease. Pathol. Int., v.55, p.130-136, 2005. 